\title{
Galicia Clínica
}

\section{La recuperación de nuestra historia y la ilusión de una nueva etapa}

\author{
Ricardo Fernández Rodríguez \\ presidente de la Sociedade Galega de Medicina Interna
}

El 25 de junio de 1983 firmaron el acta constituyente de la "Sociedade Galega de Medicina Interna" - SOGAMI - los 23 socios fundacionales. Celebramos su XXV aniversario en el presente año, como una organización bien consolidada, con 360 socios en la actualidad. Entre los proyectos que la SOGAMI ha planteado para celebrar esta importante conmemoración destaca la recuperación de Galicia Clínica.

\section{"Celebramos su XXV aniversario en el presente año, como una organización bien consolidada, con 360 socios “}

La revista Galicia Clínica, fundada en 1929 por el Dr. Aurelio Gutiérrez Moyano, tuvo una gran aceptación entre los médicos gallegos por la gran calidad de los trabajos publicados y por ser foro abierto a diferentes especialidades clínicas y a médicos generalistas a lo largo de sus 65 años de vida editorial (1929-1994). La SOGAMI tuvo a lo largo de su historia una estrecha relación con esta revista siendo con frecuencia el lugar de publicación de las comunicaciones a sus congresos y reuniones. La mejor forma de reconocer el pasado y agradecer la labor hecha por los fundadores, directores y todos los autores que dieron vida a Galicia Clínica, era recuperarla; el mejor homenaje a todos ellos era iniciar una nueva etapa como Revista Oficial de la SOGAMI. La Junta Directiva presidida por Emilio Casariego, comenzó los trámites para solicitar la cesión de la marca a sus propietarios, la familia Gutiérrez-Moyano. Gracias a la generosidad de los herederos del fundador, representados por Dña. Mercedes Gutiérrez-Moyano Zimmermann, fue fácil alcanzar un acuerdo y desde el día 11 de octubre de 2007 consta en el Registro de Marca Nacional Galicia Clínica como Revista Oficial de la SOGAMI. En este acuerdo, firmado por el que suscribe, también se incluyó la cesión de todo el fondo editorial de la revista, de forma totalmente desinteresada por parte de la familia Gutiérrez-Moyano, desde el primer número en el año 1929 hasta el último en 1994, para su conservación en un archivo histórico digital, de fácil y gratuito acceso.

En el año 2000 el presidente de la SOGAMI, Pascual Sesma Sánchez, inició las gestiones para poner en marcha el portal www.meiga.info ("medicina interna de Galicia"). Es nuestro punto de encuentro, la web oficial como órgano de expresión de la SOGAMI, que ha alcanzado un éxito relevante en contenidos y visitas. En la web existe información sobre historia de la sociedad, sus estatutos, la forma de asociarse; es el portal dónde se publicita y gestiona todas las actividades docentes y formativas de la sociedad. Dispone de enlaces con una amplia red de fondos bibliográficos y una sección de producción propia de nuestros asociados. Los apartados más visitados son los de elaboración propia y entre ellos destacan las Guías Clínicas cuyo éxito hizo posible que se editasen por primera vez en papel - "Guías Clínicas de la SOGAMI" (2006, Sociedade Galega de Medicina Interna)-.

"Entre los proyectos que la SOGAMI ha planteado para celebrar esta importante conmemoración destaca la recuperación de Galicia Clínica" 


\section{"Es un motivo de alegría para los internistas gallegos, en la conmemoración del XXV aniversario de su sociedad, en el marco de la celebración del XXIX Congreso de la Sociedad Española de Medicina Interna"}

La nueva Galicia Clínica estará muy relacionada con nuestro portal web. La Junta Directiva nombró Director de la Revista a Ramón Rabuñal, y Director Adjunto a José Luis Díaz y Rafael Monte, responsables del éxito de la web, y por tanto los más indicados para coordinar los dos organismos oficiales de expresión de nuestra sociedad.

La admiración y respeto por la etapa anterior de la revista se basa en buena parte en su espíritu abierto a todas las ramas de la medicina. Aunque en este nuevo período Galicia Clínica es la Revista Oficial de la SOGAMI, queremos mantener ese carácter abierto que ya se refleja en la composición de los Comités Editorial y Científico así como en la política de colaboración con autores de diferentes especialidades y de otras comunidades autónomas. Aumenta el número de colaboradores y las normas de publicación se basan en hacer de las páginas de la revista un foro abierto para todos los profesionales de la medicina, con especial atención a los problemas prevalentes en nuestro medio, en Galicia. Desde esa admiración por la etapa previa la SOGAMI ha apostado con decisión por esta nueva empresa, con una amplia remodelación de la Revista, un nuevo diseño, otras estructuras, nuevas secciones,... un fácil acceso en la red www.galiciaclinica.info. Ahora que ve la luz esta nueva Galicia Clínica quiero felicitar a todos los que han hecho posible esta realidad, y en especial a su Director, Ramón Rabuñal, por su arduo trabajo, su voluntad férrea y su espíritu innovador con los que se han logrado cumplir ampliamente las expectativas que la Dirección de la SOGAMI se había marcado.

Los indicios de recuperación de la Medicina Interna como especialidad, se relacionan con una mayor vitalidad de las Sociedades Científicas y sus Congresos, con más posibilidades de afrontar proyectos ambiciosos. Esta revista es uno de ellos y nos habla de una SOGAMI viva, gracias a la colaboración de todos nuestros socios que ven el futuro de nuestra sociedad prometedor, como el de la especialidad a la que nos dedicamos. Para que esta nueva época de Galicia Clínica sea exitosa precisamos de la colaboración de todos, de los médicos en formación MIR y sus tutores, desde los "internistas noveis" a los "seniors", para que continúe en el tiempo esta Revista, para que sea clave para cumplir un objetivo de nuestros estatutos "... el fomentar todas las manifestaciones científicas relacionadas con la Medicina Interna, servir de vehículo a la difusión de los trabajos científicos, a la investigación clínica...".

\section{En el año 2000 el presidente de la SOGAMI, Pascual Sesma Sánchez, inició las gestiones para poner en marcha el portal www.meiga. info ("medicina interna de Galicia")}

Como presidente de la Junta Directiva expreso aquí el orgullo y satisfacción de la SOGAMI por asistir al lanzamiento del primer número de esta nueva Galicia Clínica. Es un motivo de alegría para los internistas gallegos, en la conmemoración del XXV aniversario de su sociedad, en el marco de la celebración del XXIX Congreso de la Sociedad Española de Medicina Interna. Mis mejores deseos para que el futuro de Galicia Clínica sea al menos tan largo como en la etapa anterior; estoy seguro que, con la colaboración de todos vosotros, será con los mismos índices de calidad y dedicación. 